\title{
The enzymatic hydrolysis rate of cellulose decreases with irreversible adsorption of cellobiohydrolase I
}

\author{
Anzhou Ma ${ }^{\mathrm{a}}$, Qing $\mathrm{Hu}^{\mathrm{b}}$, Yinbo $\mathrm{Qu}^{\mathrm{a}}$, Zhihui Bai ${ }^{\mathrm{b}}$, \\ Weifeng Liu ${ }^{\mathrm{a}}$, Guoqiang Zhuang ${ }^{\mathrm{a}, \mathrm{b}, *}$ \\ a State Key Laboratory of Microbial Technology, Shandong University, Jinan 250100, China \\ ${ }^{\mathrm{b}}$ Research Center for Eco-Environmental Sciences, Chinese Academy of Sciences, Beijing 100085, China
}

\section{A R T I C L E I N F O}

\section{Article history:}

Received 11 July 2007

Received in revised form 15 December 2007 Accepted 18 February 2008

\section{Keywords:}

Cellobiohydrolase I

Hydrolysis

Irreversible adsorption

Solid-liquid interface

Rate retardation

\begin{abstract}
A B S T R A C T
Protein adsorption onto solid substrates usually takes place in an irreversible fashion and this irreversible adsorption also occurs in some enzymatic reactions. In this work the adsorption behavior of intact $\beta-1,4-$ glucan-cellobiohydrolase (CBH I) from Trichoderma reesei onto microcrystalline cellulose was monitored by surface plasmon resonance and UV-spectral method. It was found that there existed reversible binding and irreversible binding of $\mathrm{CBH}$ I during its interaction with cellulose substrate. To evaluate the influence of adsorption on cellulose enzymatic hydrolysis, the reaction dynamics on pure cellulose were determined. A plot of the hydrolysis rate against the surface density of irreversibly adsorbed CBH I, revealed an inverse relationship in which an apparent decrease in the hydrolysis rate was observed with increasing surface density. Taken together, results presented here should be useful for modifying the binding characteristics of $\mathrm{CBH}$ I and making them more effective in cellulose hydrolysis.
\end{abstract}

(C) 2008 Elsevier Inc. All rights reserved.

\section{Introduction}

The adsorption of proteins at a solid-liquid interface is a common phenomenon which has been widely observed in various areas such as biology, medicine, biotechnology, and food processing $[1,2]$. Proteins are often considered to be denatured at solid-liquid interface [1], and it has been assumed that the extent to which a protein becomes denatured is correlated with its irreversible adsorption to the interface [3]. The irreversible protein adsorption is usually unfavorable in biocatalysis, where the irreversibly bound proteins occupy a large number of surfaces while limiting the access of other functional proteins. On the other hand, the irreversibility of protein adsorption should have a great effect on the downstream processing. Regarding its important implications in medicine, biotechnology, and food processing, the irreversibility of protein adsorption on a solid surface has been extensively studied [3-5]. However, much less attention has been paid to studying the enzyme adsorption at its substrate solid-liquid interface such as in the case of cellulases acting on insoluble cellulose.

\footnotetext{
* Corresponding author at: Research Center for Eco-Environmental Sciences, Chinese Academy of Sciences, Shuang Qing Road 18, Beijing 100085, PR China. Tel.: +8610 62849613; fax: +861062923563.

E-mail addresses: weifliu@sdu.edu.cn (W. Liu), gqzhuang@rcees.ac.cn (G. Zhuang).
}

Adsorption of cellulases to the substrate cellulose surface is the first step in the enzymatic hydrolysis of cellulose. Unlike enzymatic hydrolysis with soluble substrates, adsorption of cellulases takes place at cellulose-liquid interface. Various studies on fungal cellulases have shown that once adsorbed, the desorption of the enzyme is not easy and that the binding is, at least, partly irreversible [6-9]. Adsorption and its relation to cellulose hydrolysis has been the focus of many studies. Especially, the phenomenon that the rate of cellulose hydrolysis declines dramatically as hydrolysis proceeds, called rate retardation, has been observed by many investigators [10,11]. It has been suggested that the rate of hydrolysis is proportional to the amount of adsorbed enzymes [12,13]. However, recent studies using a single purified cellulase enzyme $\beta$-1,4-glucan-cellobiohydrolase (CBH I)(EC 3.2.1.91) and a homogenous substrate showed that a declining rate of reaction was still observed at the initial stage of adsorption [14].

The reversibility and irreversibility of adsorption of CBH I onto insoluble cellulose has been demonstrated in previous studies. However, information on the role of irreversible adsorption of $\mathrm{CBH}$ I during cellulose hydrolysis is far from clear. On the other hand, most research has focused on the relationship between the rate retardation and the total adsorption, much less attention has been paid to how reversibility and irreversibility of adsorption relating with rate retardation. We, therefore, tried to understand the influence of irreversible adsorption $\mathrm{CBH}$ I on hydrolysis rate during the hydrolytic process from this point of view. In this study, the adsorption behavior of CBH I onto cellulose CF11 was monitored by 
UV-spectral method and surface plasmon resonance (SPR) which is an optical method that is usually used to register the protein mass adsorbed.

\section{Materials and methods}

\subsection{Purification of cellulase}

CBH I was purified from a commercial cellulase, Celluclast (Novo Nordisk, Tianjin, China). Before purification, Celluclast samples were ultrafiltered with a Millipore microconcentrator fitted with a $10 \mathrm{kDa}$ cut-off membrane (catalog number: PXB010A50, Millipore) and suspended in an exchange buffer. The exchange buffer was $50 \mathrm{mM}$ sodium acetate buffer ( $\mathrm{pH}$ 5.6). Ion exchange chromatography steps were performed as described previously $[15,16]$. The purity of fractions containing $\mathrm{CBH}$ I enzyme was confirmed by SDS-PAGE. Fractions with CBH I were also analyzed by measuring the activity against $p$-nitrophenyl $\beta$-D-cellobiose ( $p$-NPC). The CBH I protein concentration was determined by absorbance measurements at $280 \mathrm{~nm}$ using a molar absorption coefficient of $78,800 \mathrm{M}^{-1} \mathrm{~cm}^{-1}$ [17].

\subsection{Adsorption of $\mathrm{CBH} I$}

Adsorption of $\mathrm{CBH}$ I on cellulose was monitored by the UV-spectral method and SPR, respectively. CF11 (Whatman), used as the substrate, was prepared as follows: the cellulose was washed thoroughly with distilled water by repeated steps of centrifugation and resuspension, and then freeze-dried. Low protein binding tubes (catalog number: 508-GRDS-Q, Sangon) with CF11 suspended in $50 \mathrm{mM}$ sodium acetate buffer ( $\mathrm{pH}$ 5.0) were preincubated at the hydrolysis temperature of $40^{\circ} \mathrm{C}$ for $60 \mathrm{~min}$. Hydrolysis was carried out at $40^{\circ} \mathrm{C}$ in a shaking bath at $200 \mathrm{rpm}$. Enzyme concentration was $2.0-3.0 \mu \mathrm{M}$. The reaction was started by adding $\mathrm{CBH}$ I at $40^{\circ} \mathrm{C}$ to $1.0 \mathrm{ml}$ of CF11 suspension $(1.0 \mathrm{mg} / \mathrm{ml})$. At indicated time points, the hydrolysate was centrifuged $(10,000 \mathrm{rpm} \times 1 \mathrm{~min})$, washed repeatedly with the same buffer as the buffer in the sample pre-incubated at $40^{\circ} \mathrm{C}$, and all the supernatants were collected. The protein concentration in the supernatant was determined as described above. The mass of totally adsorbed $\mathrm{CBH}$ I was calculated by subtracting the mass of free $\mathrm{CBH} I$ in the first supernatant from the mass of the added CBH I. The CBH I still remaining on the substrate after repeated washing steps as the above mentioned protocol was regarded as irreversibly adsorbed enzyme. The mass of irreversibly adsorbed $\mathrm{CBH}$ I was calculated by subtracting the total mass of free $\mathrm{CBH}$ I in all the following supernatants from the mass of the added $\mathrm{CBH}$ I. The surface area of the cellulose was estimated by microscopic observation as previously described [18].

SPR was performed to confirm the UV-spectral method. CBH I adsorption onto the surface of CF11 was monitored in real time by the Biacore X system (Biacore AB, Uppsala, Sweden) at $40^{\circ} \mathrm{C} .50 \mathrm{mM}$ sodium acetate buffer, $\mathrm{pH}$ 5.0, was the buffer used in all SPR experiments and the buffer was prepared by filtering through a syringe filter (Millex GP, PES membrane, pore size $0.22 \mu \mathrm{m}$, diameter $25 \mathrm{~mm}$, Millipore) and ultrasonically degassing under vacuum. Immobilization of cellulose on the SPR chip surface was performed according to the affinity between biotin and streptavidin. Biotinylated cellulose was prepared using the procedure with slight modification [19]. Streptavidin was immobilized onto the CM5 chip surface using an EDC/NHSmediated amine coupling protocol [20]. CBH I was introduced to the chip surface by passing through a series volume of $\mathrm{CBH}$ I $(100 \mu \mathrm{M})$ samples in buffer during the experiments. The chip surface was automatically rinsed with the running buffer after all the samples were completely passed through the chip. Adsorption data were automatically collected by the Biacore $\mathrm{X}$ instrument and the experiment was performed thrice. The total adsorbed mass of $\mathrm{CBH}$ I was measured at a point immediately before washing with the buffer. After elution with the running buffer, the amount of $\mathrm{CBH}$ I that remained on the cellulose surface represented the irreversibly adsorbed mass [3].

\subsection{Analysis of cellobiose production and reducing ends}

The hydrolysate solution containing cellobiose was boiled for $10 \mathrm{~min}$ in a water bath followed by filtration through syringe filters (Millex GP, Millipore). Sample blanks (only substrate in solution without enzyme) were subjected to the same conditions as the experimental samples. Cellobiose, the hydrolysis product, was analyzed by HPLC [21]. The HPLC system (Shimadzu, Japan) was equipped with an Aminex HPX-87H column (Bio-Rad Laboratories). The mobile phase was $0.5 \mathrm{mM}$ sulfuric acid (filtered through a $0.22 \mu \mathrm{m}$ pore size membrane) eluting at a $0.4 \mathrm{ml} / \mathrm{min}$ flow rate. During operation, the column temperature was kept at $55^{\circ} \mathrm{C}$. Standard cellobiose was used to make a calibration curve in order to calculate the concentration of cellobiose that was produced. In the meantime, changes of cellulose reducing ends (substrate concentration) were estimated at various time points of incubation by the BCA method as described by Zhang and Lynd [22].

\subsection{CBH I activity assays and circular dichroism}

$p$-NPC was used as the substrate for assays to measure the enzymatic activity of CBH I [23]. Enzymatic activities of CBH I desorbed upon washing with buffer and
CBH I irreversibly adsorbed on cellulose were measured. CBH I irreversibly adsorbed on cellulose was resuspended in buffer with substrate $p$-NPC when assays of activity. The experiment was performed at $40^{\circ} \mathrm{C}$ in a water bath, and the mixture was shaken every $5 \mathrm{~min}$. The reaction was terminated by the addition of $1 \% \mathrm{Na}_{2} \mathrm{CO}_{3}$. Aliquots were transferred to a microtiter plate after centrifugal sedimentation $(10,000 \mathrm{rpm} \times 1 \mathrm{~min})$ of the cellulose. The released $p$-nitrophenol was determined by measuring absorbance at $400 \mathrm{~nm}$. Specific activities were recorded in terms of the release rate of $p$-nitrophenol in $\mu \mathrm{mol} / \mathrm{min}$. CBH I activities in different states were compared to assess the effects of irreversible adsorption on biological activity.

Circular dichroism (CD) spectra (200-250 nm) of different treatments of CBH I were performed on a JASCO (J-810) circular dichroism spectrometer [24]. Spectra were recorded in $1 \mathrm{~cm}$ path length quartz cuvettes with a scan rate of $500 \mathrm{~nm} / \mathrm{min}$ and a lower number of spectra. Samples of irreversibly adsorbed CBH I were selected from different indicated time points. The solution of $\mathrm{CBH}$ I was also measured and compared with that of resuspended solution of irreversibly adsorbed $\mathrm{CBH}$ I onto cellulose at identical conditions.

\section{Results}

\subsection{Adsorption isotherms}

Adsorption of $\mathrm{CBH}$ I on cellulose was monitored by means of both the UV-spectral method and SPR, respectively. The adsorbed behavior of $\mathrm{CBH}$ I and trends of adsorption isotherms were determined by the UV-spectral method and were found to be in close agreement with the results of SPR (Figs. 1 and 2). The enzyme adsorbed immediately to the substrate after being introduced to the reaction system. The initial part of the adsorption isotherm suggested that the enzyme had a high affinity for cellulose. After washing, part of the originally added CBH I still remained bound to cellulose, displaying an obviously irreversible adsorption onto the cellulose surface (Fig. 2). The trend of irreversible adsorption was similar to that of total adsorption as determined by different methods. However, the amount of adsorbed protein did not show a clear plateau, instead the percentage of irreversibly adsorbed enzyme to totally adsorbed amount showed a slow increase.

\subsection{Hydrolysis of cellulose}

The time course for changes in cellobiose concentration during hydrolysis of cellulose was investigated for different concentrations of CBH I. The hydrolytic rate is defined as $\mathrm{d} C / \mathrm{d} t$, where $C$ is the concentration of the main hydrolysis product of cellobiose. The

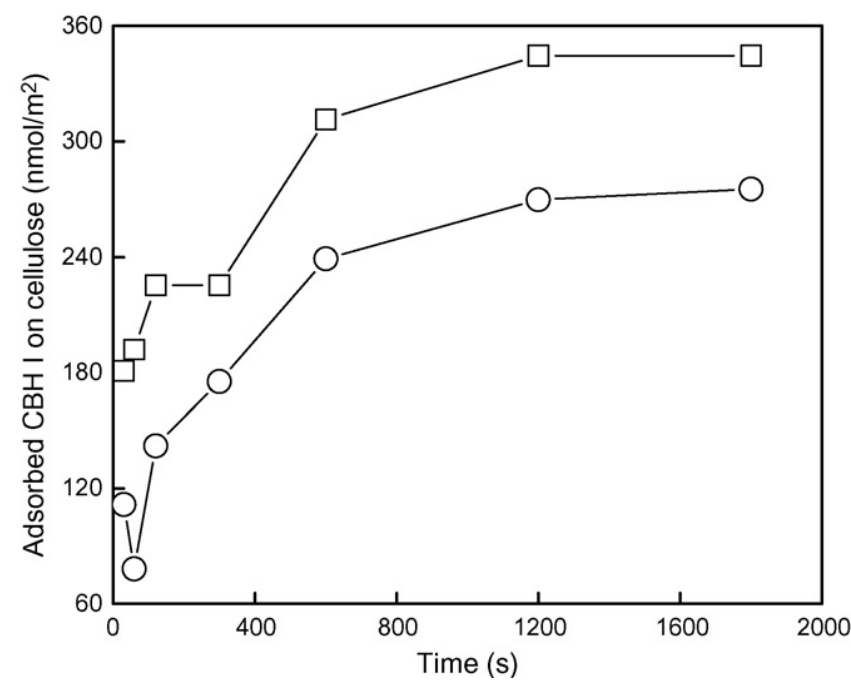

Fig. 1. Adsorption isotherms of $\mathrm{CBH}$ I onto cellulose surface measured by conventional spectra method. Cellulose $(1.0 \mathrm{mg} / \mathrm{ml})$ was incubated at $40^{\circ} \mathrm{C}$ in $50 \mathrm{mM}$ sodium acetate, $\mathrm{pH}$ 5.0, with 3.0 $\mu \mathrm{M} \mathrm{CBH} \mathrm{I.} \mathrm{total} \mathrm{adsorption} \mathrm{(} \square$ ); irreversible adsorption $(\bigcirc)$. 


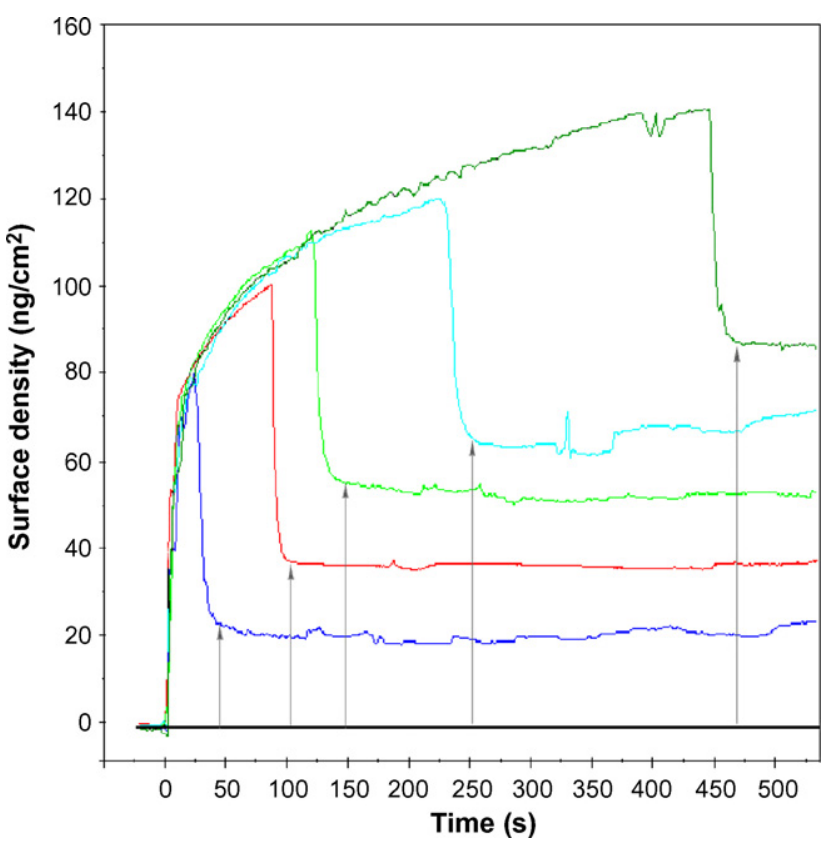

Fig. 2. Adsorption isotherms of $\mathrm{CBH}$ I onto cellulose surface measured by SPR. Arrows denote amount of irreversibly adsorbed $\mathrm{CBH}$ I at indicated time points.

hydrolytic rate started to decline upon the adsorption of $\mathrm{CBH} \mathrm{I}$, and decreased dramatically until less than $10 \%$ of the initial hydrolysis rate remained after being incubated for $10 \mathrm{~min}$ with $2 \mu \mathrm{M}$ of $\mathrm{CBH}$ I (Fig. 3). The trend showing a declining hydrolytic rate during hydrolysis was similar for various initial concentrations ( 2 and $3 \mu \mathrm{M}$ ) of $\mathrm{CBH}$ I in the reaction system (Fig. 3).

The possible influence of substrate concentration (reducing ends of cellulose) on hydrolysis rate was examined by measuring changes of reducing ends of residual cellulose at various time points of incubation by the method mentioned in Section 2. Absorbance at $560 \mathrm{~nm}$ hardly changed during the hydrolysis process indicating that the amounts of reducing ends present of residual cellulose remained nearly constant during hydrolysis (Fig. 3, inset).

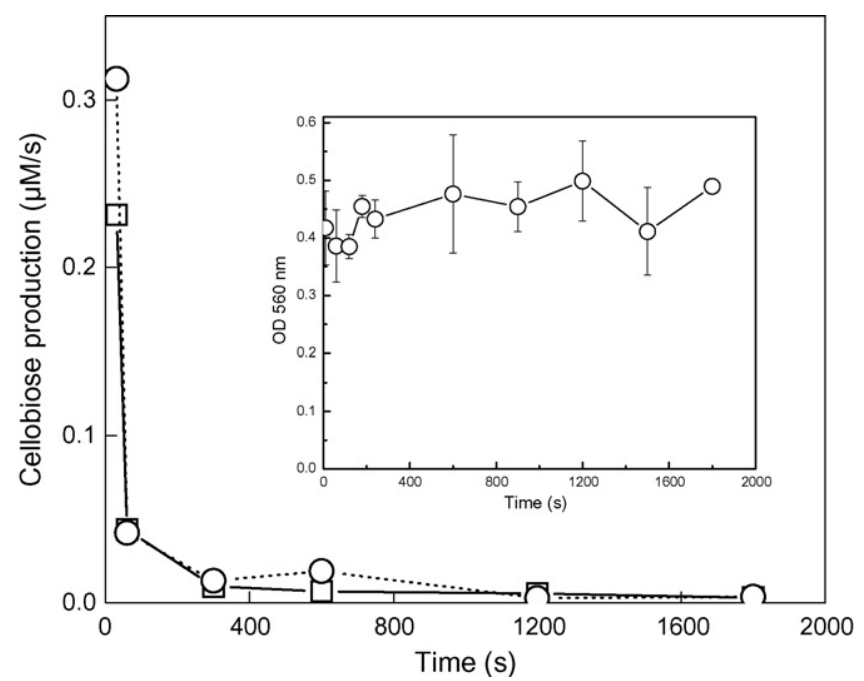

Fig. 3. Hydrolysis of cellulose with $\mathrm{CBH}$ I. Cellulose $(1.0 \mathrm{mg} / \mathrm{ml})$ was incubated at $40^{\circ} \mathrm{C}$ in $50 \mathrm{mM}$ sodium acetate, $\mathrm{pH}$ 5.0, with $3.0 \mu \mathrm{M} \mathrm{CBH} \mathrm{I}(\bigcirc)$ and $\left.2.0 \mu \mathrm{M} \mathrm{CBH} \mathrm{I} \mathrm{(} \square\right)$. Inset: Reducing ends of cellulose during hydrolysis process with $3.0 \mu \mathrm{M} \mathrm{CBH} \mathrm{I} \mathrm{were}$ measured at selected time points by BCA assay.
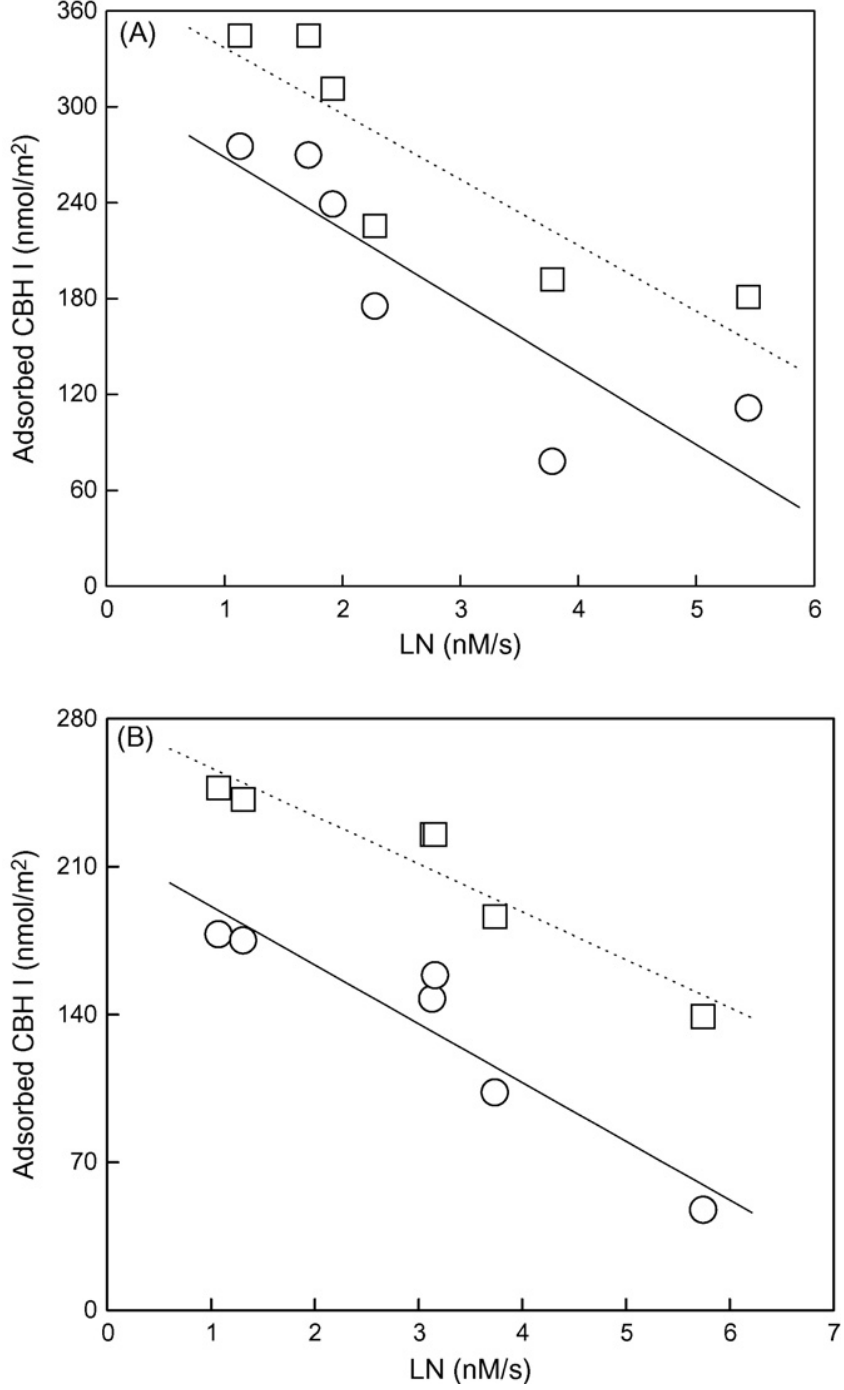

Fig. 4. Surface density of $\mathrm{CBH}$ I adsorption versus hydrolysis rate. Cellulose $(1.0 \mathrm{mg} / \mathrm{ml})$ was incubated at $40{ }^{\circ} \mathrm{C}$ in $50 \mathrm{mM}$ sodium acetate, $\mathrm{pH} 5.0$, either with $2.0 \mu \mathrm{M}$ of $\mathrm{CBH}$ I (A) or with $3.0 \mu \mathrm{M}$ of $\mathrm{CBH}$ I (B). Surface density of total adsorption was determined by $(\square)$, surface density of irreversible adsorption was measured by (○).

In order to investigate the correlation between the hydrolysis rate and adsorption, the reaction dynamics on cellulose were determined in the same reaction system. Adsorption was evaluated by UV-spectral method during the hydrolysis process as described in Section 2 . The cellulose hydrolysis rate treated by natural logarithm was plotted versus surface density of $\mathrm{CBH}$ I adsorption (i.e., the amount per unit surface area) (Fig. 4). While the cellulose hydrolysis rate for various $\mathrm{CBH}$ I concentrations was high at low surface density of adsorption, it declined with increasing surface density of irreversible adsorption.

\subsection{Properties of irreversibly adsorbed CBH I}

$p$-NPC is the widely used choice of substrate for assaying the enzymatic activity of CBH I (Fig. 5). To test our enzymatic activities of irreversibly adsorbed CBH I, samples were selected according to the adsorption isotherm. Compared with the reversibly desorbed enzymes at various time points during the process of the reaction, which still had nearly the same specific activity as originally added $\mathrm{CBH}$ I, the activities of irreversibly adsorbed CBH I on cellulose 


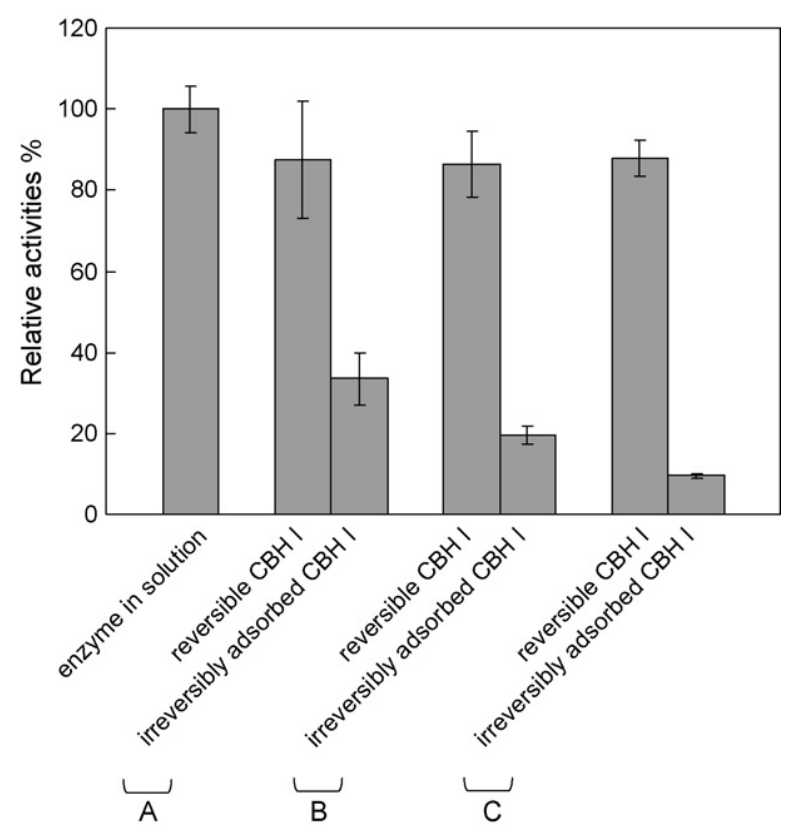

Fig. 5. Relative specific enzymatic activity of $\mathrm{CBH}$ I. Cellulose $(1.0 \mathrm{mg} / \mathrm{ml})$ was incubated at $40^{\circ} \mathrm{C}$ in $50 \mathrm{mM}$ sodium acetate, pH 5.0, with $3.0 \mu \mathrm{M}$ of $\mathrm{CBH}$ I. Relative activities were measured at different time points during hydrolysis using $p$-NPC ( $0.5 \mathrm{mM}$ in $50 \mathrm{mM}$ sodium acetate, $\mathrm{pH}$ 5.0) as a substrate. Samples were selected and measured according to the adsorption isotherm: (A) 10 min time point; (B) 20 min time point; (C) 30 min time point. The maximum enzymatic activity in solution originally added was taken as $100 \%$.

decreased dramatically. The relative specific activity of irreversibly adsorbed $\mathrm{CBH}$ I decreased by $70 \%$ after $10 \mathrm{~min}$, and the activity decreased gradually as hydrolysis proceeded. Comparison of different CD spectra graphs for irreversibly adsorbed CBH I indicated that apparently different conformations of $\mathrm{CBH}$ I were adopted during the hydrolysis of cellulose (Fig. 6). Interestingly, changes really exist in the CBH I conformation and its specific activity during irreversibly adsorbed on cellulose with hydrolysis proceeding.

\section{Discussion}

Although an understanding of the connection between binding and hydrolysis is crucial in cellulase study, decisive conclusions have been elusive so far [8]. In this study, we focused on different

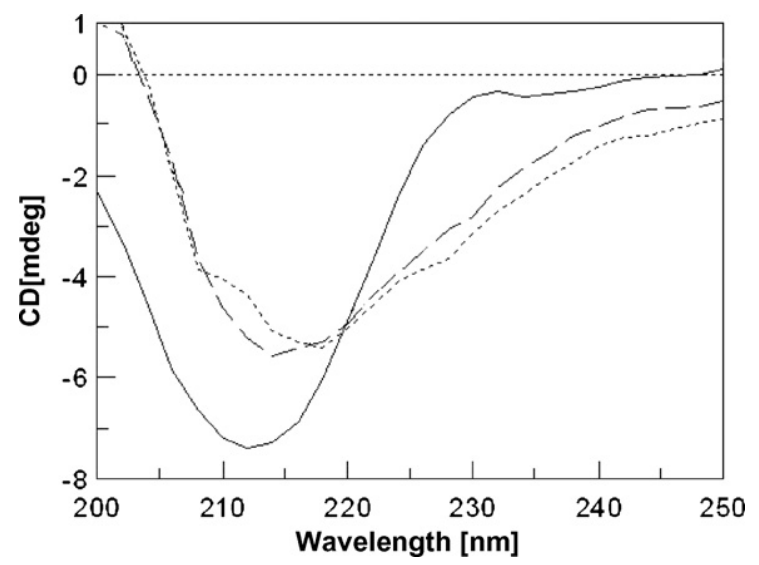

Fig. 6. Far-UV CD spectra of CBH I. Native CBH I in solution (solid line), irreversible adsorption of $\mathrm{CBH}$ I onto cellulose at $10 \mathrm{~min}$ time point (dashed line), at $30 \mathrm{~min}$ time point (dotted line). aspects of binding and hydrolysis from a dynamic point of view. We showed that there existed reversible binding and irreversible binding during the CBH I adsorption onto and hydrolysis of cellulose. Importantly, an inverse relationship was uncovered between the surface density of irreversibly adsorbed $\mathrm{CBH}$ I and the hydrolysis rate during cellulose hydrolysis.

When cellulases hydrolyze cellulose, the cellulase-cellulose complex should consist of the soluble enzyme solution and the insoluble substrate cellulose. Obviously, cellulase enzymes have to act at the solid-liquid interface during the hydrolysis of cellulose. In this context, physicochemical properties of cellulases should be in accordance with the general rule of adsorption of protein at solid-liquid interface. Indeed, we observed the irreversible adsorption of CBH I onto cellulose by different methods (Figs. 1and 2). Similar phenomena of irreversible adsorption, albeit under different conditions, were mentioned by Kyriacou et al. and Nidetzky et al. [7,9]. The most common description of cellulase adsorption is the Langmuir isotherm, assuming that adsorption can be described by a single adsorption equilibrium constant and a specified adsorption capacity [18]. However, our research showed that adsorption of CBH I onto cellulose is partially irreversible which does not comply with assumptions implicit in the Langmuir model. The binding parameters of our adsorption isotherms could not be fitted very well by an adaptation of the Langmuir model, which means that the adsorption of $\mathrm{CBH}$ I onto cellulose is not a simple phenomenon as described elsewhere.

Typical consideration about cellulase adsorption and cellulose hydrolysis is that there must be an initial stage where both binding and activity increase in parallel, which has found support in many reports [12,13]. However, these data were mostly obtained by use of cellulase mixtures. By using single $\mathrm{CBH}$ I, both data from Valjamae et al. [14] and our research in this study show that a declining rate happens initially during the enzyme adsorption stage. One reason for this discrepancy may be due to the very limited "productive" binding compared with much more "non-productive" binding. Another reason may lie in the fact that hydrolysis rate should be proportional to the concentration of substrate as the first order reaction. In this respect, since $\mathrm{CBH}$ I hydrolyzes a cellulose chain from the reducing end and moves along the same cellulose chain $[25,26]$, changes of the actual number of reducing ends in cellulose might also affect the hydrolysis rate. However, reducing ends cannot be changed by using a single CBH I (Fig. 3, inset). Nonetheless, the amount of accessible reducing ends would decrease with irreversible binding. On the contrary, in the case of cellulase complex, endoglucanase can increase new reducing ends by acting on amorphous region of cellulose until it is hindered by crystal region. This may explain why a declining rate was not observed for the cellulase mixtures while it existed at the initial stage of adsorption by using a single $\mathrm{CBH}$.

During the degradation of insoluble cellulose, only absorbed enzymes can be considered "working enzymes". Among absorbed enzymes, the specific activity of the reversible enzymes at various time points in the reaction system was nearly the same as that of $\mathrm{CBH}$ I applied in the reaction initially. But enzyme activities of the irreversibly adsorbed $\mathrm{CBH}$ I on cellulose changed dramatically (Fig. 5). This indicated that it is irreversibly adsorbed CBH I, but not the total adsorption contributes to the decreasing hydrolysis rate although a similar correlation also exists if plotted for that of total adsorption. Importantly, $\mathrm{CD}$ spectra results indicated that the conformation of $\mathrm{CBH}$ I in irreversible binding changed (Fig. 6), and they may be transferred into an unproductive state as indirectly supported by the decline of their specific activity.

Compared with the effort to explain the rate of retardation from the point of productive and unproductive status of $\mathrm{CBH}$, our results suggested that the declined hydrolysis rate could be correlated with 
the increase of irreversible adsorption considering the inseparable relationship between adsorption and hydrolysis process. Nevertheless, we did not rule out the possibility that there might exist a productive status in those irreversible bound enzymes, and the possibility that those active reversible binding enzymes contributes to the low catalytic activity in the range of several minutes to hours although hydrolysis rate become very low as compared with that at the initial stage. Further research on mechanisms of irreversible adsorption of cellulses at cellulose solid-liquid interface would be helpful for understanding cellulase rate retardation. We believe that this may provide helpful information for engineering cellulase enzymes and altering the characteristics of $\mathrm{CBH}$ I, making it more effective and increasing the hydrolysis rate.

\section{Acknowledgments}

This work was supported by grants from the National Science Foundation of China (no.30370036), the National Basic Research Foundation of China (nos.2003CB716000 and 2004CB719702) and the Fund of Glycosylation Research Group in Shandong University, China.

\section{References}

[1] Gray JJ. The interaction of proteins with solid surfaces. Curr Opin Struct Biol 2004; 14:110-5.

[2] Nakanishi K, Sakiyama T, Imamura K. On the adsorption of proteins on solid surfaces, a common but very complicated phenomenon. J Biosci Bioeng 2001;91:233-44.

[3] Karlsson M, Ekeroth J, Elwing H, Carlsson U. Reduction of irreversible protein adsorption on solid surfaces by protein engineering for increased stability. J Biol Chem 2005;280:25558-64.

[4] Sakiyama T, Tanino K, Urakawa M, Imamura K, Takahashi T, Nagai T, et al. Characteristics of tryptic fragments of bovine $\beta$-lactoglobulin on a stainless steel surface. J Biosci Bioeng 1999;88:536-41.

[5] Su TJ, Lu JR, Thomas RK, Cui ZF, Penfold J. The adsorption of lysozyme at the silica-water interface: a neutron reflection study. J Colloid Interface Sci 1998;203:419-29.

[6] Otter DE, Munro PA, Scott GK, Geddes R. Desorption of Trichoderma reesei cellulase from cellulose by a range of desorbents. Biotechnol Bioeng 1989;34:291-8.

[7] Kyriacou A, Neufeld RJ, MacKenzie CR. Reversibility and competition in the adsorption of Trichoderma reesei cellulase components. Biotechnol Bioeng 1989;33:631-7.

[8] Palonen H, Tenkanen M, Linder M. Dynamic interaction of Trichoderma reesei cellobiohydrolases Cel6A and Cel7A and cellulose at equilibrium and during hydrolysis. Appl Environ Microbiol 1999;65:5229-33.
[9] Nidetzky B, Steiner W, Claeyssens M. Cellulose hydrolysis by the cellulases from Trichoderma reesei: adsorptions of two cellobiohydrolases, two endocellulases and their core proteins on filter paper and their relation to hydrolysis. Biochem J 1994;303:817-23.

[10] Desai SG, Converse AO. Substrate reactivity as a function of the extent of reaction in the enzymatic hydrolysis of lignocellulose. Biotechnol Bioeng 1997;56:650-5.

[11] Eriksson T, Karlsson J, Tjerneld F. A model explaining declining rate in hydrolysis of lignocellulose substrates with cellobiohydrolase I (cel7A) and endoglucanase I (cel7B) of Trichoderma reesei. Appl Biochem Biotechnol 2002;101:41-60.

[12] Sattler W, Esterbaue H, Glatter O, Steiner W. The effect of enzyme concentration on the rate of hydrolysis of cellulose. Biotechnol Bioeng 1989;33:1221-34.

[13] Steiner W, Sattler W, Esterbaue H. Adsorption of Trichoderma reesei cellulase on cellulose: experimental data and their analysis by different equations. Biotechnol Bioeng 1988;32:853-65.

[14] Valjamae P, Sild V, Pettersson G, Johansson G. The initial kinetics of hydrolysis by cellobiohydrolases I and II is consistent with a cellulose surface-erosion model. Eur J Biochem 1998;253:469-75.

[15] Boer H, Teeri TT, Koivula A. Characterization of Trichoderma reesei cellobiohydrolase Cel7A secreted from Pichia pastoris using two different promoters. Biotechnol Bioeng 2000;69:486-94.

[16] Medve J, Lee D, Tjerneld F. Ion-exchange chromatographic purification and quantitative analysis of Trichoderma reesei cellulases cellobiohydrolase I, II and endoglucanase II by fast protein chromatograph. J Chromatogr A 1998;808:153-6.

[17] Stahlberg J, Johansson G, Pettersson G. Trichoderma reesei has no true exocellulase: all intact and truncated cellulases produce new reducing end groups on cellulose. Biochim Biophys Acta 1993;1157:107-13.

[18] Zhang $\mathrm{YH}$, Lynd LR. Toward an aggregated understanding of enzymatic hydrolysis of cellulose: noncomplexed cellulase systems. Biotechnol Bioeng 2004;88:797-824.

[19] Li FC, Qi X, Geng MY. A novel method of immobilization of 911 for surface plasmon resonance biosensor. Chin J Anal Chem 2003;31:266-70.

[20] Cooper MA. Label-free screening of bio-molecular interactions. Anal Bioanal Chem 2003;377:834-42.

[21] Medve J, Karlsson J, Lee D, Tjerneld F. Hydrolysis of microcrystalline cellulose by cellobiohydrolase I and endoglucanase II from Trichoderma reesei: adsorption, sugar production pattern, and synergism of the enzymes. Biotechnol Bioeng 1998;59:621-34.

[22] Zhang YH, Lynd LR. Determination of the number-average degree of polymerization of cellodextrins and cellulose with application to enzymatic hydrolysis. Biomacromolecules 2005;6:1510-5.

[23] Deshpande MV, Eriksson KE, Pettersson LG. An assay for selective determination of exo-1,4-beta-glucanases in a mixture of cellulolytic enzymes. Anal Biochem 1984;138:481-7.

[24] Koutsopoulos S, Tjeerdsma AM, Lieshout JF, van der Oost J, Norde W. In situ structure and activity studies of an enzyme adsorbed on spectroscopically undetectable particles. Biomacromolecules 2005;6:1176-84.

[25] Teeri TT, Koivula A, Linder M, Wohlfahrt G, Divne C, Jones TA. Trichoderma reesei cellobiohydrolases: why so efficient on crystalline cellulose? Biochem Soc Trans 1998;26:173-8

[26] Teeri TT. Crystalline cellulose degradation: new insight into the function of cellobiohydrolases. Trends Biotechnol 1997;15:160-7. 